\title{
Effect of machining fluid on the process performance of wire electrical discharge machining of nanocomposite ceramic
}

\author{
Chengmao Zhang ${ }^{1, a}$ \\ ${ }^{1}$ Linyi University, Shandong, China
}

\begin{abstract}
Wire electric discharge machining (WEDM) promise to be effective and economical techniques for the production of tools and parts from conducting ceramic blanks. However, the manufacturing of nanocomposite ceramics blanks with these processes is a long and costly process. This paper presents a new process of machining nanocomposite ceramics using WEDM. WEDM uses water based emulsion, polyvinyl alcohol and distilled water as the machining fluid. Machining fluid is a primary factor that affects the material removal rate and surface quality of WEDM. The effects of emulsion concentration, polyvinyl alcohol concentration and distilled water of the machining fluid on the process performance have been investigated.
\end{abstract}

\section{INTRODUCTION}

Engineering ceramics has been widely used in modern industry such as ballistic armor, ceramic composite automotive brakes, diesel particulate filters, a wide variety of prosthetic products, piezo-ceramic sensors and next-generation computer-memory products because of their higher hardness and wear resistance, lower thermal expansion coefficient and density, and chemical inertness[1,2]. However, most of the ceramic parts shaped by sintering processes cannot meet the requirements of accuracy and surface quality. Therefore the machining and surface finishing of part become necessary [3].

Ceramics are known as very difficult-to-machine materials[4]. The main reasons for this are their high hardness, non-electrical conductivity and brittleness. Diamond grinding is one of the most commonly used techniques for insulating ceramics blank shaping but it is costly and inefficient. The high hardness of ceramics induces higher grinding force and quick wear of diamond cutting edges[5-8]. Some researchers have used electrolyte as the machining fluid to achieve WEDM, EDM, EDG, arc discharge machining, gas-filled electrochemical discharge machining, and mechanical electrodischarge and electrochemical compound machining of insulating ceramics [9-13]. These processes generate harmful gas during machining. They show low efficiency, and their equipments can be easily eroded by electrolyte. Naotake Mohri et al. [14,15] have developed the techniques of WEDM and EDM non-conducting ceramics using kerosene as machining fluid. In this method, a metal plate or metal mesh is arranged on the surface of the insulating ceramics, as an assisting electrode. With the help of assisting electrode, insulating ceramics can be machined by sinking EDM or by WEDM in work oil. However, these processes of machining a large surface area on insulating ceramics show low efficiency.

Recently, Si3N4-TiN composites have received much attention because of the possibility for electrical discharge machining [16]. Nanocomposite ceramics have excellent mechanical properties at both ambient 、 elevated temperatures and good electrical conductivity, they are called "omnipotence materials" or "materials of 21 century". So the investigation of machine nanocomposite ceramic by wire electrical discharge machining (WEDM) is very important [17].

This paper proposes a new technique of machining the TiN/Si3N4 nanocomposite ceramics using WEDM. The effects of machining conditions on the material removal rate (MRR), and surface roughness $(\mathrm{Ra})$ have been investigated. In addition, the machined surfaces by the new process are examined with a scanning electron microscope (SEM). Through the comprehensive analysis of the test results, the effect law of the process parameters on the technical index of WEDM is concluded, which provides the basis for parameters selection in WEDM. The effects in emulsified soap solution or in distilled water of the machining fluid on the process performance have been investigated.

\section{PRINCIPLE FOR WEMD OF NANOCOMPOSITE CERAMICS}

The principle for WEDM of the $\mathrm{TiN} / \mathrm{Si}_{3} \mathrm{~N}_{4}$ nanocomposite ceramics is illustrated in Fig.1. WEDM machine (DK7732, Suzhou new Spark Machine Tool Co., Ltd.) is showed as Fig.2. The wire electrode and the

\footnotetext{
a Corresponding author: lydxzcm $@ 126 . c 0 m$
} 
work-piece are connected to the negative and positive poles of the impulsing power, respectively. The wire electrode is molybdenum wire with the diameter of $0.18 \mathrm{~mm}$. The wire electrode is mounted onto a rotary spindle, driven by an A.C. motor. The work-piece is bar with dimensions of $3 \mathrm{~mm} \times 4 \mathrm{~mm} \times 40 \mathrm{~mm}$ and is mounted on to a numerically controlled (NC) table.

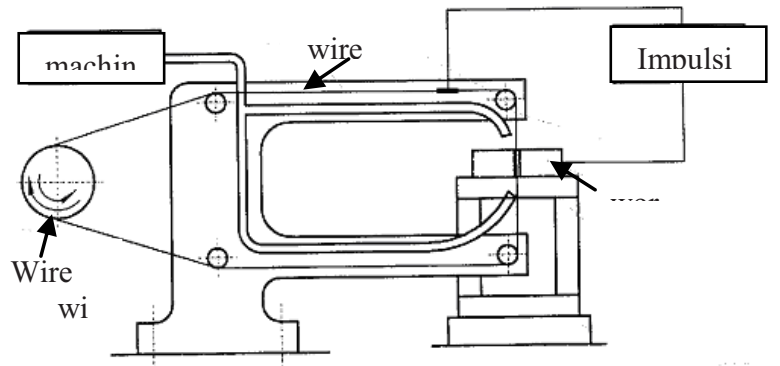

Fig 1. sketch map of WEDM.

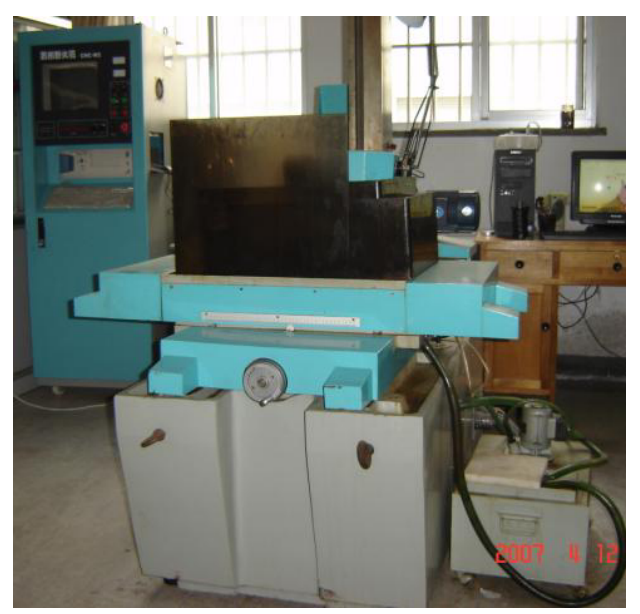

Fig 2. WEDM machine.

During machining, the wire electrode rotates at a high speed, the TiN/Si3N4 nanocomposite ceramics workpiece is fed towards the wire electrode driven by a D.C. motor. As short circuits or arcs are generated in WEDM, the workpiece is fed back by the D.C. motor. After short circuits or arcs are cleared up, the workpiece is fed on again. The machining fluid is flushed into the gap between the wire electrode and the workpiece with several nozzles. As the workpiece approaches the wire electrode and the distance between the workpiece and the electrode reaches the discharge gap, electrical discharges occur from the edge and the bottom of the electrodes. The instantaneous high temperature and pressure plasma cause TiN/Si3N4 nanocomposite to be removed by WEDM. The wire electrode are fixed on the wire winding drum, the working fluid is flushed into the gap largely, the chips are flushed away easily, the wire electrodes and the workpiece are cooled quickly; therefore WEDM improves the stability of the electrical discharges. The wire electrode rotates to ensure that the electrodes are worn homogeneously. In addition, using molybdenum wire as the electrode, the wire electrode is manufactured easily and shows low cost.

\section{MATERIALS, TEST CONDITIONS AND MEASUREMENT}

We used the TiN/Si3N4 nanocomposite ceramics bars with a resistivity of $0.1 \sim 10 \Omega \mathrm{cm}$ as work-pieces because ceramics with a low resistivity is easily cut by WEDM. The work-pieces are bars with dimensions of $3 \mathrm{~mm} \times 4$ $\mathrm{mm} \times 40 \mathrm{~mm}$, whose surfaces on each side are flat. One side surface of the bars is polished to an optical surface with an rms surface roughness of $0.5 \mathrm{~nm}$ and a peak-tovalley (PV) flatness of $2 \mu \mathrm{m}$. Then, the bars are cut in emulsified soap solution or in distilled water by WEDM. The machining fluid is emulsified soap solution or distilled water. Emulsified soap solution is composed of 20 mass\% emulsified soap (NG-1, Nanjing Nanguang electric processing new technology research institute, China) and 80 mass $\%$ distilled water, which are mixed with a constant speed power-driver mixer. The electric current is $3 \mathrm{~A}$ and discharge frequency is $80 \mathrm{kHz}$. After the cutting, we examined the effects of cutting by WEDM on the polished surfaces. All specimens are cleaned in an alcohol bath using Mini Ultrasonic Cleaner model KQ500DB and then dried using Beuhler Metaserv Specimen Dryer in blower mode. The kerf is measured using the Infinite Focus Alicona Machine as the sum of the wire diameter and twice wire-workpiece gap. The kerf value is expressed in five different spot and each spot will give ten readings, the average of these reading will be taken as kerf width. the average of it is selected. Metallurgical microscopy is used to see the macrostructure of machined surface (topography view). The results obtained will be represented in graphs and figures subsequently will be discussed.

\section{EXPERIMENTS AND DISCUSSION}

\subsection{Effect of emulsion concentration of machining fluid on the process performance}

The effect of emulsion concentration on material removal rate (MRR) and surface roughness (SR) is illustrated in Figs.3 and 4; the machining fluid was emulsified soap solution.

As shown in Fig.3, MRR initially increases fast with increase of emulsion concentration and then decreases slowly with increase in emulsion concentration.

Emulsified soap solution is composed of $20 \mathrm{mass} \%$ emulsified soap (NG-1, Nanjing Nanguang electric processing new technology research institute, China) and 80 mass \% distilled water, at this point the material removal rate of up to a maximum. There are many reasons for this. Dielectric strength, washing capability, density and viscosity of machining fluid increase with increase in emulsion concentration. Pinch-effect and energy density of discharge channel are enhanced. Ejection effect of the eroded material increases and, therefore, MRR rises. However, with a very high 
viscosity of the machining fluid it is difficult to flush away the eroded material, the stability of electrical discharges becomes unsatisfactory, and hence MRR falls. Fig. 4 shows the influence of emulsion concentration on SR. SR increases with increasing emulsion concentration. Surface roughness values change relatively flat. This is because energy density of the discharge channel increases with increase of emulsion concentration; the crater size generated by a single pulse becomes large and, therefore $\mathrm{SR}$ rises with increase in emulsion concentration.

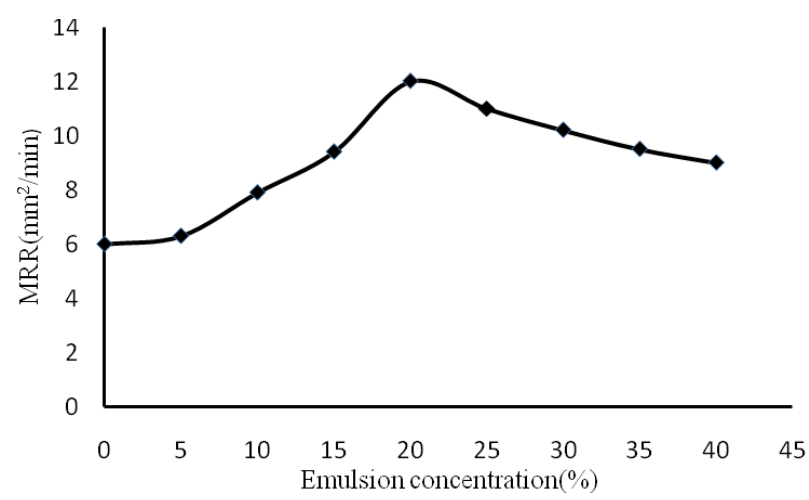

Fig.3. Effect of emulsion concentration on MRR.

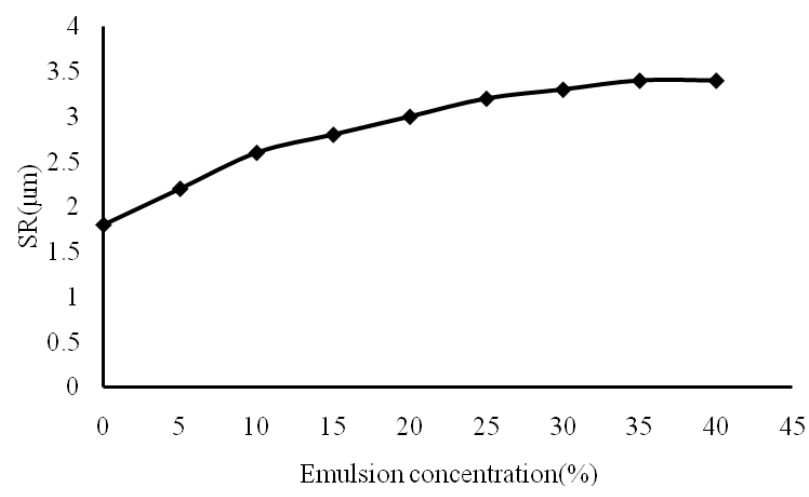

Fig.4. Effect of emulsion concentration on SR.

Fig.5(a) and (b) show that craters size generated by different emulsion concentration. The craters with emulsion concentration of $35 \%$ are higher than that of $15 \%$. Therefore, SR rises with increase in emulsion concentration.

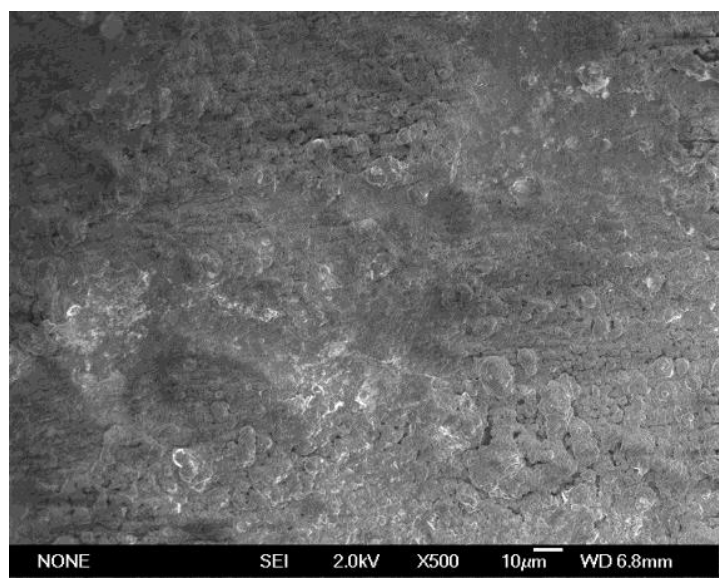

(a) $15 \%$

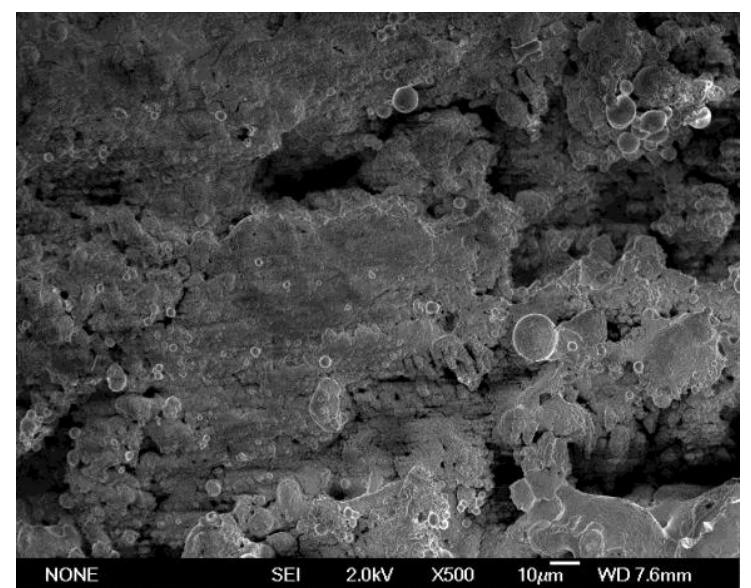

(b) $35 \%$

Fig.5. Surface photograph of the work-piece with different emulsion concentration

\subsection{Effect of polyvinyl alcohol concentration on process performance}

The effects of polyvinyl alcohol (PVA) concentration on MRR and SR are illustrated in Figs.6 and 7. The machining fluid was $10 \%$ emulsion + water + PVA.

As shown in Fig.6, MRR initially increases with PVA concentration increase and then decreases with an increase in PVA concentration. Polyvinyl alcohol concentration is composed of 0.5 mass $\%$, at this point the material removal rate of up to a maximum. The reason for this is that dielectric strength and viscosity of the machining fluid increase with increase in PVA concentration, energy density of the discharge channel and discharge breakdown explosion force rise. Therefore MRR is high. As PVA concentration is higher than a suitable value, the eroded material is difficult to flush away. The stability of electrical discharges becomes unsatisfactory, and hence MRR falls [8].

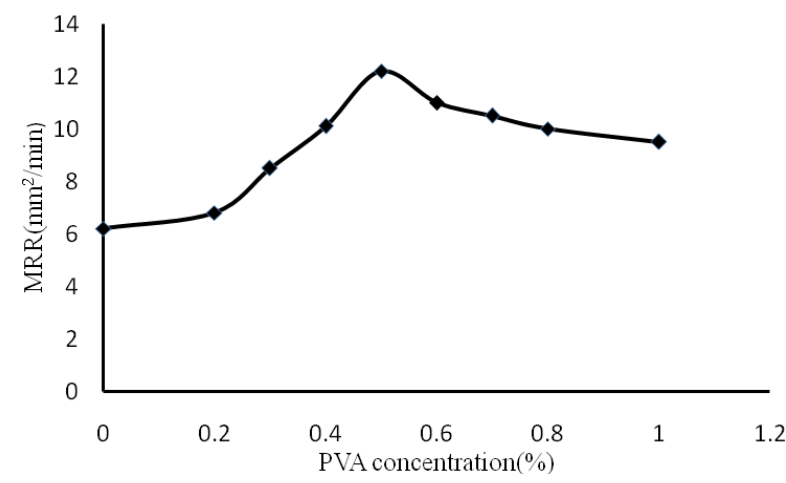

Fig.6. Effect of PVA concentration on MRR.

Fig. 7 shows the influence of PVA concentration on SR. SR increases with PVA concentration. This is because energy density of the discharge channel and discharge breakdown explosion force increase with increase in PVA concentration. Crater size generated by a single pulse becomes large. 


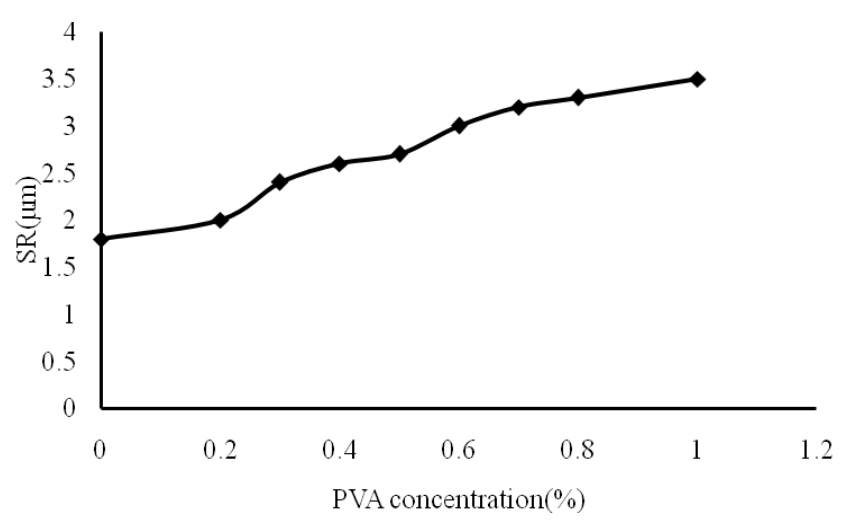

Fig.7. Effect of PVA concentration on SR

\subsection{Effect of fluids on kerf width}

Fig.8 (a) and (b) shows the photos of the polished surfaces near the cut sections, which are observed with a differential interference contrast microscope, a Metallurgical microscopy; It shows the average kerf width as function of different machining dielectric fluids obtained in our WEDM experiment, in which pulse width is $57 \mu \mathrm{s}$ 、Open voltage is $75 \mathrm{~V}$, pulse duration is $440 \mu \mathrm{s}$ and worktable speed is $270 \mu \mathrm{m} / \mathrm{min}$. Fig.8 (a) and (b) show surfaces cut in emulsified soap solution and in distilled water, respectively. The photos show that the kerf widths are approximately $230 \mu \mathrm{m}$ for the surfaces cut in emulsified soap solution and $300 \mu \mathrm{m}$ in distilled water. It is found that both polished surfaces cut in emulsified soap solution and in distilled water exhibit defects such as rough regions, chips, and cracks; in particular, such defects occur near the cut sections. As shown in Fig.8(a), for cutting in emulsified soap solution, we can observe chips and cracks near the cut section although the entire surface is smooth, maintaining the initial surface; chips are generated up to $20 \mu \mathrm{m}$, and cracks up to $30 \mu \mathrm{m}$ from the cut section. On the other hand, for cutting in distilled water, as shown in Fig.8 (b), chips are generated up to 50 $\mu \mathrm{m}$, and the polished surfaces are significantly roughened up to $110 \mu \mathrm{m}$ from the cut section. Furthermore, areas far from the cut sections are somewhat rough, with several pits at various places.

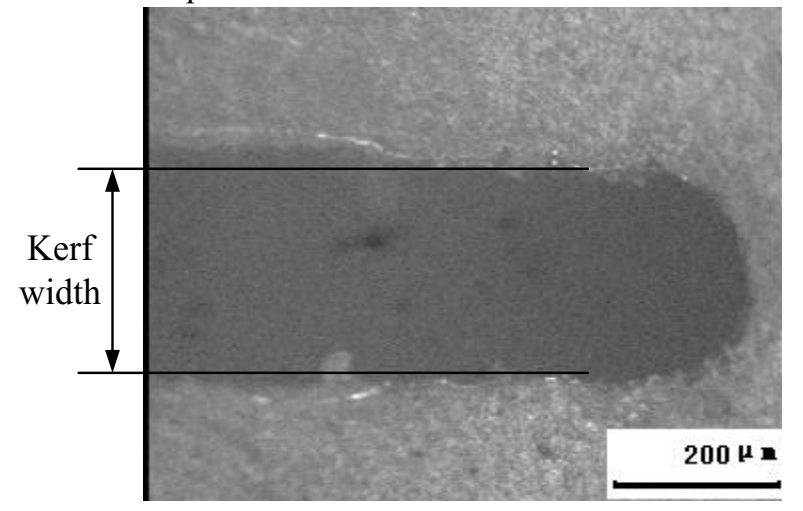

(a) emulsified soap solution

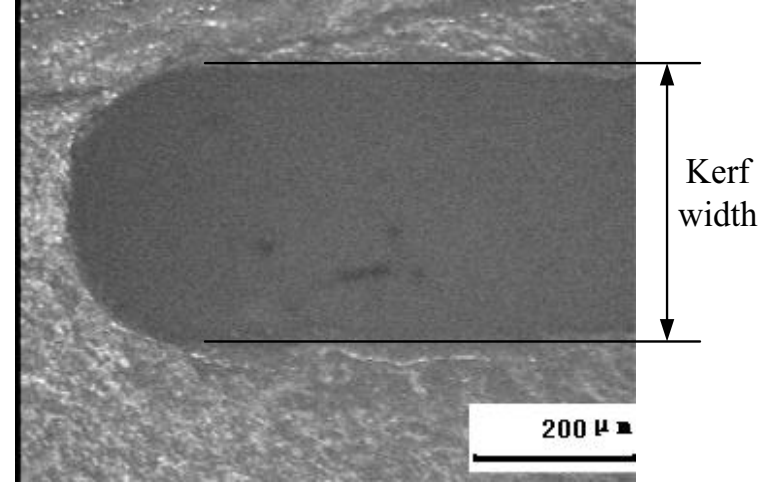

(b) distilled water

Fig.8. Observation of the polished surfaces near sections using a differential interference contrast microscope, a Metallurgical microscopy.

\section{CONCLUSIONS}

(a) With a suitable emulsion concentration, high machining rate and good surface quality of the machining the TiN/Si3N4 nanocomposite ceramics can be easily obtained by WEDM.

(b) MRR initially increases with PVA concentration increase and then decreases with an increase in PVA concentration. SR increases with PVA concentration.

(c) As a result, these findings indicate WEDM in emulsified soap solution is better than that in distilled water for cutting the TiN/Si3N4 nanocomposite ceramic to obtain small kerf width.

\section{ACKNOWLEDGMENTS}

Lian Gao,Xihai Jin provided the TiN/Si3N4 nanocomposite ceramics of State Key Lab on High Performance Ceramics and Superfine Microstructure, Shanghai Institute of Ceramics, Chinese Academy of Sciences. And all those who contributed directly or indirectly are thanked. This work is supported by A Project of Shandong Province Higher Educational Science and Technology Program (Grant No. J14 LB59) and A Project of Linyi 2014 Science and Technology Program (Grant No. 201414028).

\section{REFERENCES}

1. Anon, USA advanced ceramics demand, Materials Technology 20, 168(2005)

2. S.W. Yao, H. Wang, S.L. Wang, The study and application of the special ceramics, Industrial Heating 35, 1-4(2006)

3. J.H. Du, Y.H. Liu, X.P. Li, C.Y. Miao, N.G. Hong, Z.M. Xiao, The grinding technology of engineering ceramics, Materials for Mechanical Engineering 29, 1-6 (2005)

4. N. Mohri, Y.T. Fukuzawa, T. Sata, Some considerations to machining characteristics of insulating ceramics - towards practical use in industry, Annals of the CIRP 51, 161-164 (2002) 
5. S. Agarwal, P. Venkateswara Rao, A new surface roughness prediction model for ceramic grinding, Proceedings of the Institution of Mechanical Engineers, Part B: Journal of Engineering Manufacture 219, 811821(2005)

6. X.P. Li, Y.H. Liu, R.J. Ji, L.L. Yu, Non-traditional machining technique for insulating engineering ceramics, Electromachining \& Mould 40, 6-9(2006)

7. A.V. Gopal, P.V. Rao, Modeling of grinding of silicon carbide with diamond wheels, Mineral Processing and Extractive Metallurgy Review 23, 51-63(2002)

8. Y.H. Liũ̃, R.J. Ji, X.P. Li, L.L. Yu, H.F. Zhang, Q.Y. $\mathrm{Li}$, Effect of machining fluid on the process performance of electric discharge milling of insulating $\mathrm{A} 12 \mathrm{O} 3$ ceramic, International Journal of Machine Tools \& Manufacture 48, 1030-1035 (2008)

9. Y.F. Guo, J.C. Bai, G.Q. Deng, Z.S. Lu, High-speed wire electrical discharge machining (HS-WEDM) phenomena of insulating Si3N4 ceramics with assisting electrode, Key Engineering Materials 339, 281-285 (2007)

10. Y.H. Liu, Z.X. Jia, J.C. Liu, Study on hole machining of non-conducting ceramics by gas-filled electrodischarge and electrochemical compound machining, Journal of Materials Processing Technology 69, 198-202(1997)

11. Y. Fukuzawa, H. Gotoh, N. Mohri, T. Tani, Line swept surface generation on insulating ceramics by wire electrical discharge machining, Journal of the Australasian Ceramic Society 4, 17-21 (2005)

12. B. Bhattacharyya, B.N. Doloi, Experimental investigations into electrochemical discharge machining (ECDM) of non-conductive ceramic materials, Journal of Materials Processing Technology 95, 145-154(1999)

13. Y.F. Guo, J.C. Bai, H.S. Liu, J.C. Liu, N. Mohri, Y. Fukuzawa, The study of the process of machining insulating ceramics by electrical discharge grilling, Electromachining \& Mould 40, 54-64(2006)

14. Y.T. Tani, N. Mohri, A. Muttamara, Micro hole electrical discharge machining on insulating ceramics with pipe electrode, International Journal of Electrical Machining 8, 57-61 (2003)

15. T. Tani, Y. Fukuzawa, K. Furutani, N. Mohri, Machining process of insulating ceramics by electrical discharge machining, Journal of the Japan Society for Precision Engineering 63, 1310-1314(1997)

16. Lee, B. T., Yoon, Y. J. and Lee, K. H., Microstructural characterization of electroconductive Si3N4-TiN Composites. Mater. Lett., 47, 71-76( 2001)

17. Lian Gao, Jingguo Lia, Takafumi Kusunoseb, Koichi Niiharab. Preparation and properties of TiN-Si3N4 composites. Journal of the European Ceramic Society. 24:381-3(2004) 